\title{
Spinal Cord Injury: A Model of Central Neuropathic Pain
}

\author{
Robert P. Yezierski \\ Comprehensive Center for Pain Research and the McKnight Brain Institute University of Florida, \\ Gainesville, Fla., USA
}

\section{Key Words \\ Spinal cord injury - Central pain • Excitotoxicity • Plasticity · Secondary injury}

\begin{abstract}
The condition of pain after spinal cord injury (SCI) affects the life quality of nearly $70 \%$ of individuals with SCI. Clinical studies over the past decade have provided important insights into the complexities of the clinical and psychosocial characteristics of this debilitating consequence of SCl. The use of experimental models developed to study at-level or below-level pain has provided an appreciation for the mechanism(s) responsible for the onset and progression of these conditions. Important to the studies related to $\mathrm{SCl}$ pain has been the focus on the molecular, biochemical, anatomical, and functional consequences of $\mathrm{SCl}$ that have identified potential therapeutic targets for the design of novel treatment strategies.
\end{abstract}

Copyright (c) 2005 S. Karger AG, Basel

\section{Introduction}

Pain is a debilitating consequence of spinal cord injury (SCI) related to the nature of the lesion, neurological structures damaged, and secondary pathophysiological changes of surviving tissue [1]. Clinical observations reveal specific pain syndromes associated with SCI, each with their own unique characteristics $[2,3]$. Through the use of different experimental models, valuable insights related to the potential mechanism(s) responsible for the onset of pain after injury have been obtained [1, 4]. The purpose of this article is to review the clinical and experimental studies focusing on selected pain states associated with spinal injury. A special emphasis will be placed on studies related to pain of central origin, perhaps the most disabling of all sensory complications associated with SCI [5-9].

Although loss of sensory and motor function are regarded as the most significant consequences of SCI, the condition of pain has a direct relationship with the ability of patients to regain an optimal level of activity and quality of life. The significance of SCI pain was revealed in a postal survey in which $11 \%$ of those responding reported pain rather than loss of motor function prevented them from working [10]. The functional impact of pain following SCI is further demonstrated by a study reporting $37 \%$ of SCI patients with high thoracic or cervical lesions reported that they would trade pain relief for any chance of regaining motor function [11]. For individuals with SCI the challenge of dealing with pain is surpassed by only the decreased ability to walk, loss of sexual function and bladder and bowel dysfunction [12].

The prevalence of SCI pain ranges from 65 to $80 \%$ depending on the method of data acquisition and type of pain considered [13]. With an estimated 11,000 new injuries each year in the United States and a total of more than 600,000 individuals with SCI, it is easy to appreciate the challenge this condition places on the health care system. At present there is no universally accepted classification system of SCI pain and because of this there is

\section{KARGER}

Fax +4161306 1234 E-Mail karger@karger.ch www.karger.com
C 2005 S. Karger AG, Basel

1424-862X/05/0144-0182\$22.00/0

Accessible online at:

www.karger.com/nsg
Dr. Robert P. Yezierski

Department of Orthodontics, University of Florida

1600 S.W. Archer Road, PO Box 100444

Gainesville, FL 32610 (USA)

Tel. +1 352392 4081, Fax +1 352392 3031, E-Mail ryezierski@dental.ufl.edu 
little consistency of terminology used to describe different pain states $[2,3,14]$. Recently, a Task Force of the International Association for the Study of Pain proposed a taxonomy based on the type of pain, location, and putative mechanism of pain onset [2]. Having a taxonomy that is accepted and used by specialists in the fields of pain and spinal injury should lead to advances in epidemiological studies as well as clinical and basic research.

\section{Clinical Characteristics}

Pain associated with SCI is typically perceived in anesthetic regions below the level of injury and is usually bilateral. It is often referred to as deafferentation pain, dysesthetic pain or central dysesthesia syndrome [2, 8 , $13,14]$. Commonly used descriptors of this type of pain include burning, tingling, numbness, aching and throbbing. Although it is often difficult to allocate pain types to specific categories, it appears that below-level neuropathic pain is the most common and most difficult to treat $[2,15]$. Other types of pain associated with SCI include at-level and above-level pain syndromes [2, 3]. There are other types of pain associated with SCI, including nociceptive pain secondary to overuse of skeletal muscles, neuropathic pain resulting from damage to spinal or peripheral nerves, and pain of visceral origin which have been discussed elsewhere and will not be addressed in this article [2, 3, 13, 14].

\section{Pathophysiology of Spinal Cord Injury}

In order to understand the spinal and supraspinal mechanisms responsible for SCI pain it is important to acknowledge that associated with spinal injury are biochemical, molecular, and anatomical changes that collectively have a devastating impact on the functional integrity of the spinal cord. The study of these changes requires clinically relevant animal models. It is also important to recognize that the clinical consequences associated with SCI, including at-level and below-level allodynia, hyperalgesia, and spontaneous pain represent the primary pain syndromes associated with SCI $[2,3]$. In recent years, the focus of basic research related to SCI induced pain has been devoted to the study of these two categories of pain. At-level pain associated with damage at or near the site of injury has been modeled by ischemic, excitotoxic, and contusive injury to the spinal cord [16-20]. Below-level neuropathic pain has been modeled by the contusion model, the interruption of specific white matter tracts, and lesions restricted to the gray matter in an attempt to identify the critical anatomical substrates responsible for the physiological and behavioral abnormalities associated with segments below the site of injury [21-23].

The mechanism of pain after SCI involves a cascade of events triggered by ischemic or traumatic insult to the cord. The condition of pain is a consequence of injury and to understand the end result, it is important to appreciate the sequence of events preceding the onset of this condition. One obvious consequence of SCI is the significant structural damage leading to the reorganization of spinal and supraspinal circuits responsible for the integration and processing of sensory information. Ischemic and traumatic insult to the cord also initiates a cascade of dynamically interdependent events that include changes in the expression of neurochemical systems responsible for maintaining the homoeostatic balance between inhibitory and excitatory pathways [24, 25]. Equally important are the cellular events that impact signaling, transduction, and survival of spinal neurons. Collectively, the complex sequence of primary and secondary injury-induced events has a profound impact on the survivability and excitability of spinal sensory neurons and ultimately on evoked and resting sensibilities.

Important components in the sequella contributing to the cascade of secondary injury include, but are by no means limited to, the release of toxic mediators that are by-products of excitotoxic and inflammatory processes. Beginning with injury-induced elevations of excitatory amino acids (EAAs), and continuing with the up- and down-regulation of mRNA's for cytokines and death inducing ligands, activation of astrocytes and microglia, initiation of inflammatory, immune, and excitotoxic cascades, and the activation/inactivation of transcription factors, these events influence and ultimately compromise the structural and functional integrity of spinal neurons [26-33]. The end result of these responses to injury is a devastating affect on sensory and motor systems, and over time the onset of secondary complications, including spasticity, abnormal sensations, and pain.

In recent years, the field of spinal injury has focused on achieving an understanding of the basic biology of secondary events associated with ischemic and traumatic injury. With regard to the study of pain, the goal of this research is recognized as pivotal to understanding the mechanisms of pain onset and in designing effective treatments. Not to be overlooked in the study of SCI pain are the often neglected remote effects of SCI, including deafferentation of supraspinal sensory relay nuclei, eleva- 
tions in forebrain blood flow, and increased expression of opiate transmitters in selected supraspinal sites [34-36]. Although it is not known what contribution these remote effects have on the development of chronic pain states following SCI, they cannot be ignored as part of the central mechanism of pain onset and as potential targets of therapeutic intervention.

\section{Secondary Injury Cascade following Spinal Cord Injury}

A critical event in the aftermath of SCI is the transient elevation in EAAs and the production of a wide variety of potentially toxic mediators including: (a) endogenous opioids (dynorphin); (b) prostaglandins; (c) cytokines; (d) nitric oxide, and (e) reactive oxygen species. Using an excitotoxic model of SCI that simulates the injury-induced elevations in EAAs it was found that there was an upregulation of mRNA's for IL-1 $\beta$, COX-2, iNOS and death inducing ligands CD-95 and tumor necrosis factorrelated apoptosis-inducing ligand (TRAIL) [37]. Up-regulation of messenger RNA for c-fos, TNF- $\alpha$ and dynorphin along with activation of transcription factors NF- $\mathrm{KB}$ and ELK-1 have also been reported following SCI [33, $38-40,84]$. Activation of the nuclear factor-к B (NF-кB) family of transcription factors is an especially significant event considering the fact that NF- $\kappa \mathrm{B}$ is a critical step in the inducible regulation of over 150 genes involved in inflammatory, proliferative and cell death responses [41]. A comprehensive analysis of the molecular events following spinal cord injury using DNA microarray analysis has shown that $1 \mathrm{~h}$ after trauma there are changes in mRNA levels for 165 genes [42]. In this analysis, SCI affected mRNA levels of genes that regulate transcription factors, inflammatory processes, cell survival, and membrane excitability. Importantly, a number of secondary messengers up-regulated in response to CNS injury play a pivotal role in determining the functional state of spinal sensory neurons. Another consequence of injury that may be linked to changes in neuronal excitability and the onset of abnormal sensations following SCI is the up-regulation of sodium channels $\left(\mathrm{Na}_{\mathrm{v}} 1.3\right)$ [43]. The pathological sequella of SCI is therefore by no means simple nor is it restricted to the site of insult. In summarizing different components of the secondary injury cascade one can include anatomical, neurochemical, excitotoxic, and inflammatory components that collectively interact through a process of dynamic reciprocity to influence the functional state of spinal sensory neurons, ultimately leading to the onset of abnormal sensory states including allodynia, hyperalgesia, and pain (fig. 1).

The sequence of pathological events following SCI illustrates the potential for the creation of a permissive environment conducive to the development of chronic pain. The secondary components of injury that are likely to have an important role in the onset of chronic pain include secondary pathophysiological processes and biochemical events that contribute to secondary injury and cell death (e.g. membrane damage, systemic and local vascular effects, inflammation, electrolyte imbalances, altered energy metabolism, release of transmitters, excitotoxicity and activation of multiple cellular signaling pathways) $[44,45,55,56]$.

\section{Biochemical Consequences of Spinal Cord Injury}

One of the earliest responses to spinal injury is the breakdown of cellular membranes and subsequent activation of phospholipases. Within minutes of injury, trauma-initiated lipid peroxidation and membrane hydrolysis release polyunsaturated fatty acids that are capable of causing damage through arachidonic acid and eicosanoid pathways [44]. Reactive oxygen species (ROS) can also cause damage and are by-products of these cascades. ROS can trigger excitotoxic reactions (glutamate and quinolinate), catecholamine oxidation, mitochondrial leaks, oxidation of extravasated hemoglobin, neutrophil infiltration, and microglial activation. Extravasation of heme after neural trauma also contributes to ROS production [46-47].

Membrane lipid peroxidation (MLP) is a free radicalmediated biochemical reaction whereby lipid peroxides are formed within cell membranes and organelles. MLP is a major cause of oxidative stress in injured cells involving free radical attack on the double bonds of polyunsaturated fatty acids that comprise membrane phospholipids to form lipid peroxides within cell membranes and organelles. MLP-mediated membrane disruption is followed by the loss of membrane-bound ionic pumps, transporters and receptors; ionic homeostasis, cell signaling, glucose uptake, and neurotransmitter clearance. MLP is one of the first measurable biochemical events following SCI and produces ROS and aldehydes known to initiate multiple toxic injury cascades, and therefore is a primary candidate for being one of the central destructive events of secondary injury that likely contributes to a compromise of neuronal function [47-49]. 


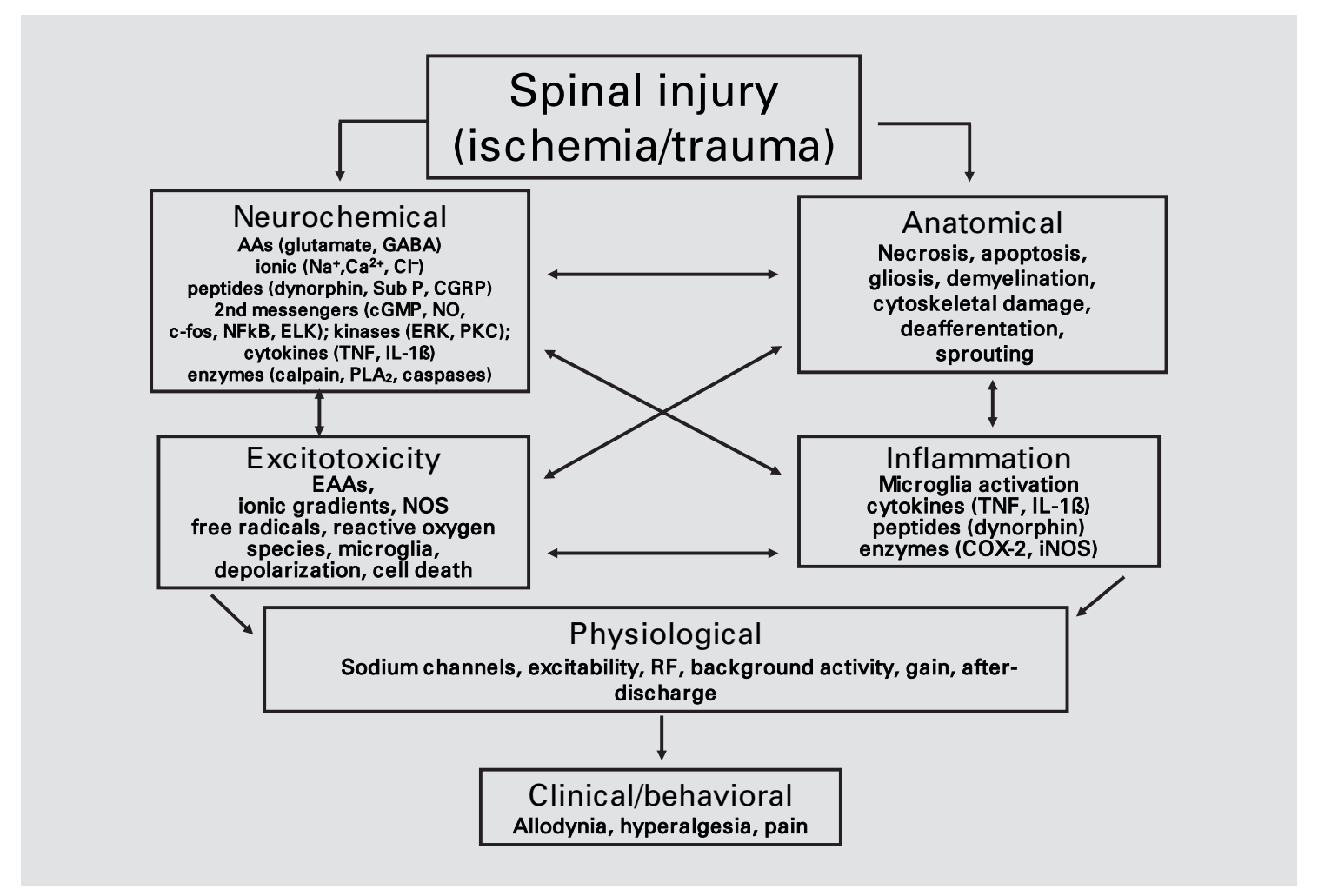

Fig. 1. Components of the spinal injury cascade that contribute to the mechanism responsible for the development of pain. Evidence supporting the involvement of this cascade comes from results of clinical and experimental studies involving mechanical, ischemic and/or chemical models of spinal injury (see text for details). The four major components of the cascade (neurochemical, excitotoxicity, anatomical and inflammation) are represented as interactive and collectively lead to conditions producing functional changes in spinal and supraspinal neurons. The end-point of the cascade is the onset of clinical and behavioral symptoms, e.g. allodynia, hyperalgesia, and pain. AAs = Amino acids; Sub $\mathrm{P}=$ substance $\mathrm{P}$; cGMP = cyclic guanidine monophosphate CGRP = calcium gene related peptide; $\mathrm{NO}=$ nitric oxide; $\mathrm{NFkB}=$ nuclear factor kappa $\mathrm{B}$; $\mathrm{PKC}=$ protein kinase $\mathrm{C} ; \mathrm{ERK}=$ extracellular signal-regulated kinase; $\mathrm{TNF}=$ tumor necrosis factor; IL-1 = interleukin-1; $\mathrm{PLA}_{2}=$ phospholipase A2; iNOS = inducible nitric oxide synthase; COX-2 = cyclooxygenase-2; RF = receptive field. Reprinted with permission from Yezierski [73].
Another consequence of the breakdown of cellular membranes is the malfunction of $\mathrm{Ca}^{2+}$ and $\mathrm{Na}^{+} / \mathrm{K}^{+}$ATPase ionic pumps with resultant disruption of sodium, potassium and calcium gradients [49]. Within hours, ionic shifts are followed by massive edema at the injury site due to cellular swelling, expansion of the extracellular space, loss of blood-spinal cord barrier (BSCB) and vascular integrity. Because of the physical damage to membranes and transporters and sustained depolarization, there are dramatic shifts of sodium from the extracellular to intracellular compartments and from surrounding tissues and blood to the extracellular milieu [50]. While sodium and potassium fluxes mediate cell death directly by disruption of intracellular and extracellular fluid and electrolyte balance, alterations in cellular calcium compartmentalization influences cell signaling pathways that can lead to mitochondrial dysfunction and apoptotic cell death. All of these events can have a dramatic impact on the functional state of spinal neurons and ultimately on the development of chronic pain.

Within the first 15 min postinjury, there are marked increases in intracellular and large decreases in extracellular calcium [51-52]. Despite the fact that extracellular calcium remains depressed, total tissue calcium is elevated. Calcium enters cells by way of voltage-sensitive calcium channels, reversal of the sodium-calcium exchange pump, through holes in the cell membranes and via excitotoxic mechanisms mediated by glutamate receptors. Because calcium is directly involved in multiple intracellular signaling pathways, and participates in cross-talk with countless others, increased intracellular calcium has profound injurious effects. Increased intracellular calci- 
um leads to augmented production of damaging ROS as by-products of eicosanoid production, activation of nitric oxide synthase and mitochondrial reactions. The derangement of calcium compartmentalization is one of the most significant pathophysiological events of SCI, as many of the deleterious reactions of secondary injury are mediated at some point by calcium signaling events [53]. Even though the full extent of biochemical and molecular changes initiated by SCI are not entirely defined, the changes documented provide insights into potential strategies targeting cellular events that might facilitate the restoration of functional homeostasis.

The above biochemical events associated with SCI set the stage for significant functional changes both at the level of the spinal cord as well as remote sites located at supraspinal levels of the neuraxis. Changes in the level of neuronal excitability, denervation supersensitivity, inactivation/activation of cell signaling cascades and changes in glial-neuronal interactions are all consequences of primary and secondary injury that potentially contribute to the onset of abnormal sensory processing and development of chronic pain following injury.

\section{Animal Models of SCI Pain}

A number of experimental models have been used in the study of SCI, each with distinctive characteristics related to specific aspects of the human condition. An important feature of these models is that each is based on a critical component of the primary injury, such as trauma or ischemia. Evidence for dysesthesia/pain and enhancement of pain-like responses at the level of spinal lesions has been provided by models using excitotoxicity [19, 59], ischemia [18, 20, 58], and contusion injury [16, 17, 60]. The excitotoxic model simulates elevated levels of excitatory amino acids that occur after injury [54, 57]. The behavioral consequences of this injury include a hypersensitivity to mechanical and thermal stimuli and spontaneous overgrooming targeting dermatomes representing segments at the lesion epicenter [19]. The photochemical model produces graded lesions from the dorsal surface of the cord down through the gray and white matter (depending on the severity of injury). This model results in an ischemic-like condition within the cord due to the blockade of blood flow within spinal vessels. The pathological results of this model are damage to the gray and white matter and the enhancement of responses to stimuli delivered to dermatomes near the level of injury $[18,58]$.
The most widely used model of SCI is the weight drop or contusion model. Although this model is believed to be the most clinically relevant, it is difficult to use in studies of sensory function due to the presence of hindlimb paresis or paralysis after injury. Another approach used in the study of altered sensation after SCI involves selected spinal lesions, including hemisection of the cord, either alone or in combination with other manipulations [21-23, 61, 62]. All of these experimental strategies share the distinction of producing pathological and/or behavioral changes associated with human SCI, and each provides an opportunity to study different aspects of the spinal or supraspinal mechanisms responsible for pain associated with SCI.

\section{Animal Models of At-Level Pain}

In spite of evidence supporting the notion that cellular or axonal loss predisposes an individual to either at-level or below-level pain, it is important (from the standpoint of determining therapeutic strategy) to distinguish between these regionally distinct categories of pain. After SCI, the occurrence of pain tends to follow a progressive sequence from at-level to below-level pain, suggesting the existence of common or interactive mechanisms. This temporal profile of pain progression raises the possibility that abnormal neural activity (spinal/supraspinal) associated with at-level pain predisposes an individual to the development of below-level pain. Additionally, the potential influence of abnormal activity from gray matter damage may influence the development of below-level pain only when a specific pattern or amount of white matter damage occurs.

Animal models of at-level pain have been used to characterize the anatomical, biochemical, molecular, physiological, and pharmacological characteristics associated with this type of pain [1]. The results implicate the involvement of a complex central cascade that includes various components believed to exert a profound influence on the functional state of spinal sensory neurons (fig. 1). The importance of the longitudinal spread of secondary cellular reactions in the development of at-level pain was shown in studies using neuroprotective and anti-inflammatory agents that suppress abnormal activity of neurons and reduce the spread of injury-induced tissue damage $[63,64]$. For example, administration of NMDA antagonists can attenuate ischemic damage, prevent the development of segmental hypersensitivity, and reduce chronic pain from SCI in humans $[9,64]$. Repeated doses of 
the antiepileptic agent gabapentin alleviate chronic hypersensitivity in spinally injured rats, and adrenal chromaffin cells that produce a 'therapeutic cocktail' of neuroprotective and analgesic agents have been used to alleviate injury induced pain behaviors [23, 65-67].

As mentioned above one approach used to study the mechanisms of at-level pain centers around the well-documented injury-induced elevation of EAAs. The excitotoxic model has been used to investigate the pathophysiological, molecular and behavioral events after transient increases in spinal levels of EAAs [1, 19, 34-36, 68, 73, 84]. A signature behavioral outcome of this model, i.e. excessive grooming behavior, is associated with a pattern of neuronal loss that includes the neck of the dorsal horn with sparing of the superficial laminae [1, 19]. Previously, it has been speculated that laminae I projection neurons might be part of the substrate for the onset of injury-induced excessive grooming behavior [19]. Support for this hypothesis was obtained using a conjugate of substance $\mathrm{P}$ with the neurotoxin saporin (SP-SAP). Application of this conjugate at the time of injury to eliminate neurokinin-1 receptor (NK-1R) expressing neurons in the superficial laminae significantly reduced the onset time and severity of excessive grooming behavior [68]. Further confirmation of this hypothesis was obtained when the severity of grooming and area of skin targeted for grooming behavior was significantly reduced when SP-SAP was delivered to the injury site after onset of excessive grooming behavior. Together these results support the involvement of NK-1R expressing neurons in lamina I as a critical neuronal substrate involved in the onset and progression of this at-level pain behavior.

Mechanisms underlying the onset of excessive grooming behavior have been further studied by evaluating the effects of three drugs targeting different components of secondary injury [63]. Although the actions of agmatine (NMDA antagonist, NOS inhibitor), interleukin-10 (IL10, anti-inflammatory) and cyclosporin A (CsA, immunosuppressant) are different, each has been shown to have neuroprotective properties and/or modulatory effects on neurons in models of excitotoxic, ischemic, or traumatic CNS injury. The results of this study showed that agmatine, IL-10 and CsA delayed the onset of excessive grooming, reduced the grooming area and grooming severity, and reduced neuronal loss in the spinal cord compared to saline-treated animals [63]. Treatment of excessive grooming behavior after onset with the same drugs significantly reduced grooming area, grooming severity, and neuronal loss in the spinal cord compared to saline treatment. The conclusion from this study was that systemic administration of agmatine, IL-10 or CsA had beneficial effects on the onset and progression of injury-induced spontaneous pain behavior. Other studies related to excessive grooming behavior have shown that gender, strain and gonadal hormones also influence the onset and progression of excessive grooming behavior following excitotoxic SCI [69].

Collectively, the results of the above studies show that there is a critical distance of neuronal loss along the longitudinal axis of the cord; when exceeded, leads to the expression of pain-related behaviors [63, 69]. Neuroprotective interventions that limit the spread of neuronal loss result in the prevention or delayed onset of these behaviors. These studies thus support a neuroprotective hypothesis of SCI pain [1] and point to the possibility that neuroprotective strategies targeting selected components of the spinal injury cascade may be useful in the prevention or treatment of pain conditions associated with SCI. The fact that gender, strain, and hormonal effects were observed and that neuroprotective as well as neurotoxic agents could be used to prevent and/or treat these behaviors suggests the need to consider a wide variety of additional therapeutic strategies for the treatment of SCI pain.

Not to be ignored in the mechanism of at-level pain are studies pointing to the potential involvement of descending influences, primarily excitatory, in the onset and maintenance of chronic pain states. Recent studies have shown the importance of pathways originating in the region of the rostral ventromedial medulla (RVM) as critical in the development of chronic pain behavior [70-72]. Given the abnormal discharges in sensory neurons known to develop secondary to SCI, it is likely that this input reaches RVM neurons that in turn complete a spino-bulbo-spinal feedback loop that exacerbates the hyperexcitable state of neurons in the spinal cord. The potential role of descending monoaminergic transmitter systems in the development and maintenance of SCI pain states needs further consideration.

\section{Animal Models of Below-Level Pain}

Although it is generally agreed that interruption of spinothalamic axons is likely to contribute to below-level SCI pain, interruption of other spinal pathways and/or abnormal activity in rostrally conducting systems is also likely to participate in the establishment of below-level pain $[4,60]$. Below-level pain after SCI may, for example, involve damage to the dorsal columns, because pain as- 
sociated with syringomyelia is reported to be more prevalent when a central cavity expands to include dorsal pathways [74]. Similarly, animal models of dysesthesia/ pain have shown that interruption of the dorsal or dorsolateral columns increases the incidence of overgrooming/ autotomy after peripheral nerve injury, and allodynia/hyperalgesia is observed in response to stimulation caudal and ipsilateral to dorsolateral column lesions in monkeys. These results suggest that damage to dorsal spinal pathways are involved in the production of SCI below-level neuropathic pain.

Historically, the spinothalamic tract has been implicated in the production of chronic central pain [75] and below-level SCI pain has been regarded as dependent upon partial deafferentation of rostral targets of the spinothalamic and associated pathways. Below-level pain may be expressed when portions of rostral targets are deprived of input from classic pain pathway(s) and are indirectly activated by other sources of input [1]. Interruption of one anterolateral quadrant reliably results in contralateral hypoalgesia, but some animals eventually develop contralateral and ipsilateral dysesthesia/pain or allodynia/hyperalgesia. In an attempt to combine ischemic damage of the gray matter with spinothalamic tractotomy, Vierck et al. [21] introduced blood into anterolateral lesion cavities of rats. Animals with these lesions were hypersensitive to stimulation ipsilateral to the lesion. Contralateral sensitivity was variable over time for all animals (alternating between hypoalgesia and allodynia). Other studies have shown that hemisection lesions at T13 result in bilateral enhancement of responses to noxious stimuli for both forelimbs and hindlimbs of rats. The behavioral effects of hemisection are accompanied by evidence for bilateral spinal reorganization (i.e. sprouting) [22-23]. Thus, below-level effects of unilateral spinal lesions on nociception do not appear to be limited to a unilateral distribution.

One of the challenges in studying below-level pain is finding a behavioral measure that effectively engages neuronal substrate(s) thought to be involved in producing this type of pain. It is generally agreed that below-level pain has a spinal as well as supraspinal (including thalamic and cortical) components. Therefore, to effectively evaluate below-level pain it is necessary to use a behavioral measure that engages both of these components. At present, behavioral measures using operant tasks as the basis for behavioral responses are the only outcome measures that meet these criteria. For this reason to effectively study below-level pain one must use an operant behavioral task. Behavioral measures including licking, guarding, orientation, vocalizations, withdrawal, and flexion are all preserved following decerebration. These segmental or spinobulbospinal reflex responses are important measures of nociception that reveal the excitability of spinal circuits following injury. However, enhancement of flexion/withdrawal reflexes (i.e. the spastic syndrome) can be dissociated from chronic below-level pain in individual cases of subtotal SCI [76, 77], and they do not represent the component of pain perception requiring cerebral processing of sensation [78]. In contrast, operant tests require cortical structures for the processing, planning and execution of tasks in a complex environment [77]. Unlike reflex responses these tasks require cortical processing, an important component required for belowlevel pain.

Using operant escape responses it has been possible to show that excitotoxic lesions at the T8 level of the cord produce enhanced thermal sensitivity without effects on reflex lick/guard responses [Yezierski and Vierck, unpubl. obs.]. Thus, it is possible to model below-level pain with an injury paradigm that produces damage restricted to the gray matter and which uses operant responses as the behavioral outcome measure. Gray matter damage appears to be an important factor in the development of below-level pain as a recent clinical study in patients with and without below-level pain showed that a common pathological feature in patients with below-level pain was the involvement of lesions that included a central core of spinal gray matter [79]. The excitotoxic model of spinal injury in combination with operant behavioral measures therefore appears to be a suitable model for the study of below-level pain.

In conclusion, well established animal models indicate that at-level SCI pain results from excitotoxic/ischemic damage to the spinal gray and white matter. Experimental models have identified putative mechanisms for generation of at-level pain and have suggested a number of potential therapeutic approaches, including pharmacological strategies targeting inhibitory systems or spinal mediators of cell survival. Of special importance is control over secondary signaling and survival pathways along with injury-induced chemical and molecular changes that modulate neuronal activity. Additionally, current evidence suggests that restricting the extent of excitotoxicity/ischemia after SCI might prevent the development of at-level neuropathic pain, both by reducing excitatory influences and by limiting gray matter damage. Below-level neuropathic pain does not appear to result only from interruption of spinothalamic projections to rostral targets, but is potentiated by interruption and/ 


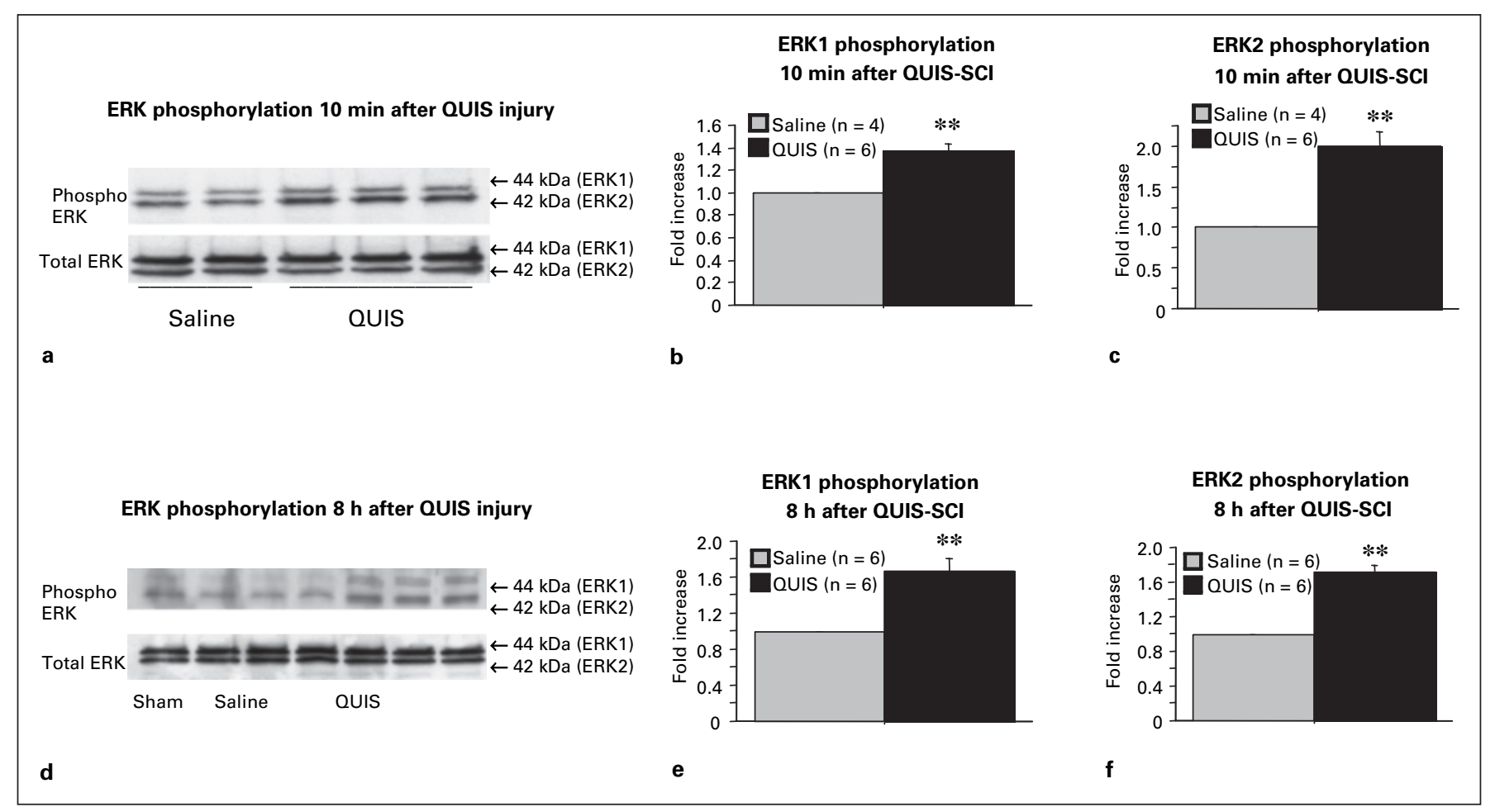

Fig. 2. Injury induced up-regulation of ERK1/2 phosphorylation. a Western blots showing injury induced ERK phosphorylation of serine residues of both ERK-1 (44 kDa) and ERK-2 (42 kDa) compared with saline-injected controls $10 \mathrm{~min}$ after intraspinal injection of QUIS. The bottom panels show levels of total ERK-1 and ERK-2 protein expression, as loading controls. Antibodies on the top panels were specific for the phosphorylated form of the ERK proteins. b Quantification of ERK-1 phosphorylation 10 min after QUIS injury evaluated by levels of fold of blot density. The fold represents comparative levels over corresponding saline-injected animals after normalizing for loading controls. c Quantification of ERK-2 phosphorylation 10 min after QUIS injury. The fold represents comparative levels over corresponding saline-injected animals after normalizing for loading controls. d Western blots show- ing injury induced ERK phosphorylation of both ERK-1 and ERK-2 compared with saline $8 \mathrm{~h}$ after intraspinal injection of QUIS. The bottom panels show levels of total ERK-1 and ERK-2 protein expression, as loading controls. Antibodies on the top panels are specific for the phosphorylation form of the ERK proteins. e Quantification of ERK-1 phosphorylation $8 \mathrm{~h}$ after QUIS injury. The fold represents comparative levels over the corresponding saline-injected animals after normalizing for loading controls. f Quantification of ERK-2 phosphorylation $8 \mathrm{~h}$ after intraspinal injection of QUIS. The fold represents comparative levels over the corresponding saline-treated animals after normalizing for loading controls. ${ }^{* *} \mathrm{p}<0.01, \mathrm{n}=$ number of tissue blocks evaluated. Reprinted with permission from $\mathrm{Yu}$ and Yezierski [84].

changes as well as later transcription-dependent changes in effector genes. Neuroplasticity resulting from these events includes activity-dependent changes in neurons and specific signaling molecules in signal transduction pathways. These changes likely contribute to alterations in the state of excitability that ultimately contributes to the development of spinal, and possibly supraspinal, pain generators.

In a study of changes in the MAPK signaling pathway following excitotoxic spinal injury there was: (1) increased phosphorylation of ERK1/2; (2) increased activation of NF- $\mathrm{BB}$ and phosphorylation of ELK-1, and (3) increased gene expression for the NK-1 receptor and NR1 and NR- 


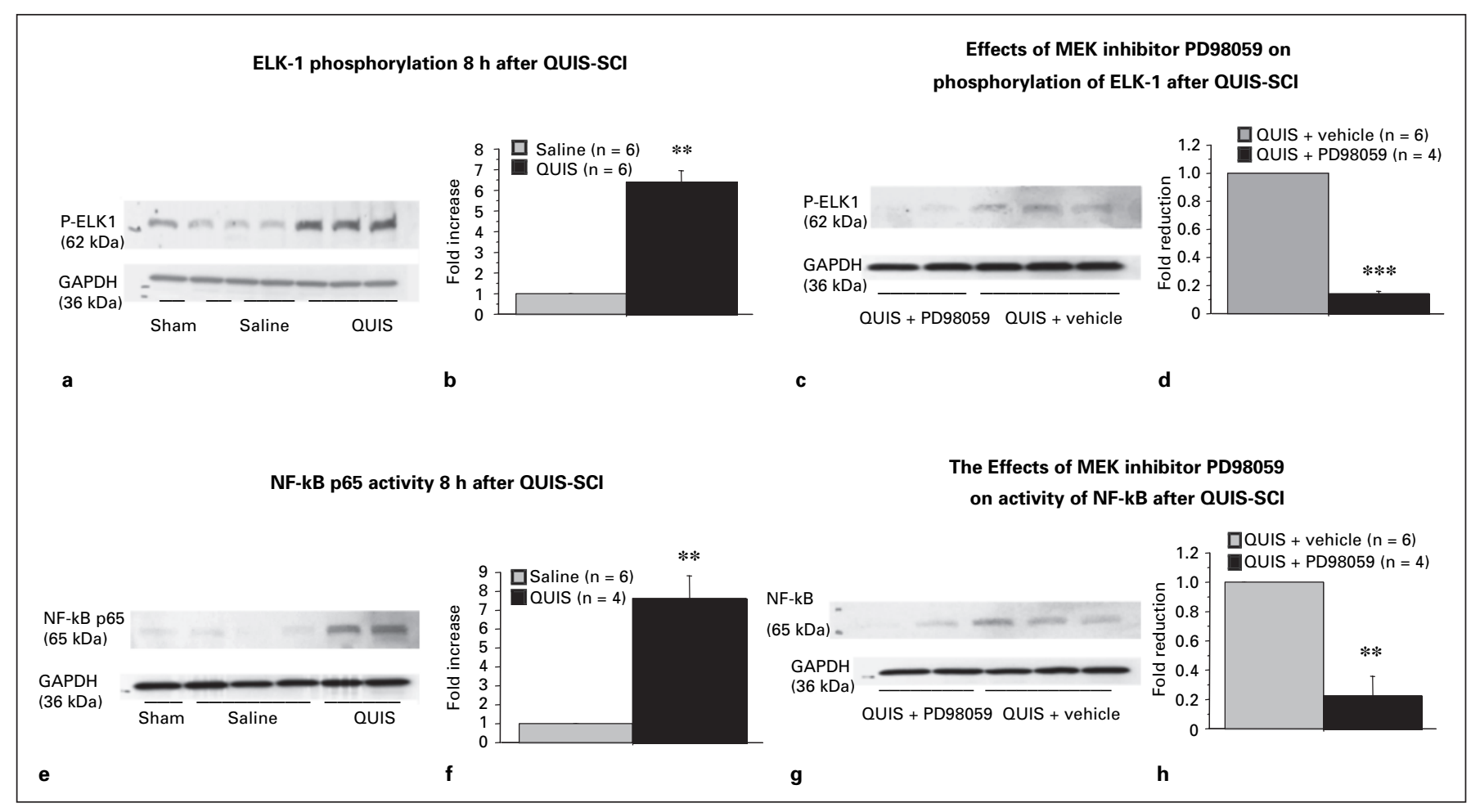

Fig. 3. Injury induced up-regulation of ELK-1 phosphorylation and NF-кB p65 activity and blockade by the MEK inhibitor PD98059. a Western blot analysis showing increased phosphorylation of ELK-1 $8 \mathrm{~h}$ after QUIS-induced injury compared with saline-injected or sham-operated animals. The bottom panels show levels of a constitutively expressed protein, GAPDH, as loading controls. b Quantification of phosphorylation of ELK-1 $8 \mathrm{~h}$ after QUIS-induced injury by the fold of blot density. c Pretreatment with PD98059 (intrathecally, $1 \mu \mathrm{g} / 15 \mu \mathrm{l}$ ) decrased ELK-1 phosphorylation $8 \mathrm{~h}$ after QUIS injury, compared to vehicle-pretreatment plus QUIS injury. The bottom panels show a constitutively expressed protein, GAPDH, that was used as a loading control. d Quantification of ELK-1 phosphorylation following pretreatment with PD98059 $8 \mathrm{~h}$ after QUIS injury. Fold reduction represents comparative reduction over corresponding vehicle-pretreatment plus QUIS injury after normalizing for loading controls. e Western blot analysis showing increased expression of activated NF- $\kappa \mathrm{B} 8 \mathrm{~h}$

2A subunits of the NMDA receptor [84] (fig. 2, 3). Blockade of the MAPK cascade with the MEK inhibitor PD98059 inhibited phosphorylation of ELK-1, activation of NF-kB and gene expression of NR1, NR-2A and NK-1R, and prevented the development of spontaneous pain behavior. Injury-induced elevations in spinal levels of EAAs thus lead to the activation of the ERK $\rightarrow$ ELK-1 and NF- $\kappa$ B signaling cascades and the transcriptional regulation of receptors important in the development of chronic pain. Blockade of these intracellular kinase cascades prevents the onset of an injury-induced pain behav- after QUIS-induced injury compared to saline injected animals. The bottom panels show a constitutively expressed protein, GAPDH, used as a loading control. $\mathbf{f}$ Quantification of activation levels of NF-кB p65 $8 \mathrm{~h}$ after QUIS-induced injury. The fold represents comparative levels over corresponding saline-injected animals after normalizing for loading controls. g Pretreatment with PD98059 (intrathecally, $1 \mu \mathrm{g} / 15 \mu \mathrm{l}$ ) decreased NF-KB p65 activity $8 \mathrm{~h}$ after QUIS injury, compared to vehicle-pretreatment plus QUIS injury. The bottom panels show a constitutively expressed protein, GAPDH, used as a loading control. $\mathbf{h}$ Quantification of NF-kB p65 activity following pretreatment with PD $980598 \mathrm{~h}$ after QUIS injury. Fold reduction represents comparative levels over corresponding vehicle-pretreatment plus QUIS injury after normalizing for loading. $* * \mathrm{p}<0.01, * * * \mathrm{p}<0.001, \mathrm{n}=$ number of tissue blocks evaluated. Reprinted with permission from $\mathrm{Yu}$ and Yezierski [84].

ior. The above results suggest that the same complement of molecular changes described as activity-dependent following peripheral nerve or tissue injury can also be induced following spinal injury. This suggests the spinal mechanism responsible for the increased excitability of sensory neurons following spinal injury may be similar to the well documented activity-dependent mechanism induced by damage to peripheral nerves and/or tissue, a mechanism resulting in the activation of intracellular kinase cascades and ultimately long-term changes in neuronal excitability. 


\section{Supraspinal Changes Associated with Spinal Cord Injury}

Supraspinal changes associated with spinal injury have been evaluated to determine whether responses to injury extend to sites remote from the spinal cord. Changes at supraspinal sites could potentially contribute to the central mechanisms responsible for the onset and progression of below-level pain behaviors. Studies carried out include measuring changes in forebrain blood flow [34], and evaluation of opiate transmitters in selected supraspinal sites $[35,36]$. In the study by Morrow et al. significant increases in regional cerebral blood flow were found in 7/22 structures, including the arcuate nucleus, hindlimb region of S1 cortex, parietal cortex and the thalamic posterior, ventral posterior medial and lateral nuclei. All of these structures have well-documented roles in sensory processing and are likely to be involved in the central mechanism of altered sensation following SCI. Work from Brewer and colleagues focused on peptidergic transmitter systems at spinal and supraspinal levels following excitotoxic SCI $[35,36]$. Preproenkephalin (PPE) and preprodynorphin (PPD) expression increased in cortical regions associated with nociceptive function; PPE in the cingulate cortex and PPD in the parietal cortex, both ipsilateral and contralateral at various time-points following injury. The increases in PPD were significant in animals that developed excessive grooming behaviors versus those that did not. PPE expression in the anterior cingulate cortex and PPD expression in the contralateral parietal cortex were significantly higher in grooming versus non-grooming animals. The important conclusion from these reports is that following injury to the spinal cord there are significant changes at selected cortical sites, including somatosensory structures that have a putative role in pain processing. These results complement a recent report in humans using proton magnetic resonance spectroscopy showing thalamic changes in the concentration of selected metabolites in SCI patients with pain [80].

\section{Future Directions}

The condition of pain associated with spinal injury is unlikely to have a simple mechanism that relies exclusively on any one consequence of injury. It is more probable that several components of a central injury cascade contribute to the development of different pain states. The precise mechanism is likely to depend on the nature of the injury and progression of pathological and molecular changes along the rostrocaudal axis of the cord, and include anatomical and functional changes occurring in supraspinal structures. The mechanism is likely to include a combination of deafferentation resulting from spinal lesions combined with tonic excitatory input from a generator of abnormal activity in or around the epicenter of gray matter damage [1]. There are clearly many possible scenarios by which the biochemical cascade initiated by injury can influence changes in the physiological properties of spinal neurons to peripheral stimuli. Continued research directed towards specific components of the spinal cord injury cascade should provide a better understanding of spinal and supraspinal mechanism(s) responsible for this condition leading to the future development of novel therapeutic strategies.

Clinical and experimental studies directed toward understanding the mechanism(s) of SCI pain are essential for identifying the critical events responsible for the onset of this condition. Progress in understanding central pain after SCI will require a commitment to clinically relevant experimental models. For the development of new treatment strategies, it will be important to remember that chronic pain is a complex condition dependent not only on many factors defined by pathophysiological and neurochemical changes within the spinal cord, but also by psychosocial factors affecting the patient. For this reason, research related to the clinical characteristics of this condition is also critical if we are to accomplish the goal of developing effective long-term clinical treatments.

\section{Acknowledgments}

The author would like to thank Drs. Brewer, Plunkett, Yu, and Gorman for their contribution to the work described and to Gladys Ruenes, Dimarys Sanchez, and Linda Daniels for their expert technical assistance. This work was supported by NS40096 (R.P.Y.). 


\section{References}

1 Yezierski RP: Spinal cord injury pain: general mechanisms; in Cervero F, Jensen TS (eds): Handbook of Clinical Neurology. Volume on Pain. Amsterdam, Elsevier, 2005.

2 Siddall PJ, Yezierski RP, Loeser JD: Taxonomy and epidemiology of spinal cord injury pain; in Yezierski RP, Burchiel KJ (eds): Spinal Injury Pain: Assessment, Mechanism, Management, Progress in Pain Research and Management. Seattle, IASP Press, 2002, vol 23, pp 9-23.

3 Hicken BL, Putzke JD, Richards JS: Classification of spinal cord injury pain: literature review and future directions; in Yezierski RP, Burchiel K (eds): Spinal Cord Injury Pain: Assessment, Mechanisms, Management. Seattle, IASP Press, 2002, pp 25-38.

$\checkmark 4$ Vierck CJ, Yezierski RP: Pain following spinal cord injury: animal models and mechanistic studies. Pain 2001;89:1-5.

$>5$ Beric A, Dimitrijevic M, Lindblom U: Central dysesthesia syndrome in SCI patients. Pain 1988;34:109-116.

-6 Davidoff G, Roth E, Guarracini M, Sliwa J, Yarkony G: Function limiting dysesthetic pain syndrome among traumatic SCI patients: A cross sectional study. Pain 1987;29:39-48.

7 Bonica JJ: Semantic, epidemiologic and educational issues of central pain; in Casey KL (ed): Pain and Central Nervous System Disease: The Central Pain Syndromes. New York, Raven Press, 1991, pp 13-29.

8 Davidoff G, Roth E: Clinical characteristics of central (dysesthetic) pain in spinal cord injury patients; in Casey KL (ed): Pain and Central Nervous System Disease: The Central Pain Syndromes. New York, Raven Press, 1991, pp 77-83.

$\checkmark 9$ Eide PK, Stubhaug A, Stenehjem AE: Central dysesthesia pain after traumatic spinal cord injury is dependent on N-methyl- $D$-aspartate receptor activation, Neurosurgery 1995; 37: 1080-1087.

10 Rose M, Robinson JE, Ellis P, Cole JD: Pain following spinal injury: results from a postal survey. Pain 1988;34:101-102.

$\checkmark 11$ Nepomuceuno C, Fine PR, Richards JS, Gowens H, Stover SL, Rantanuabol U, Houston R: Pain in patients with spinal cord injury. Arch Phys Med Rehab 1979;60:605-609.

12 Widerstrom-Noga EG: Evaluation of clinical characteristics of pain and psychosocial factors after spinal cord injury; in Yezierski RP, Burchiel KJ (eds): Spinal Injury Pain: Assessment, Mechanism, Management, Progress in Pain Research and Management. Seattle, IASP Press, 2002, vol 23, pp 53-82.

13 Yezierski RP: Pain following spinal cord injury: the clinical problem and experimental studies. Pain 1996;68:185-194.

14 Nashold BS Jr: Paraplegia and pain; in Nashold BS Jr, Ovelman-Levitt $\mathrm{J}$ (eds): Advances in Pain Research and Therapy. Deafferentation Pain Syndromes: Pathophysiology and Treatment. New York, Raven Press, 1991, vol 19, pp 301-319.
15 Finnerup NP, Johannesen IL, Sindrup SH, Fbach FW, Jensen TS: Pharmacological treatment of spinal cord injury pain; in Yezierski RP, Burchiel KJ (eds): Spinal Injury Pain: Assessment, Mechanism, Management, Progress in Pain Research and Management. Seattle, IASP Press, 2002, vol 23, pp 341-351.

16 Hulsebosch CE, Xu G-Y, Perez-Polo JR, Westlund KN, Taylor CP, McAdoo DJ: Rodent model of chronic central pain after spinal cord contusion and effects of gabapentin. J Neurotrauma 2000;17:1205-1217.

17 Siddall P, Xu CL, Cousins M: Allodynia following traumatic spinal cord injury in the rat. Neuroreport 1995;6:1241-1244.

18 Wiesenfeld-Hallin Z, Hao J-X, Aldskogius H, Seiger $\AA$, Xu X-J: Allodynia-like symptoms in rats after spinal cord ischemia: An animal model of central pain; in Boivie J, Hansson P, Lindblom U (eds): Touch, Temperature and Pain in Health and Disease: Mechanisms and Assessments. Progress in Pain Research and Management. Seattle, IASP Press, 1994, pp 355-372.

19 Yezierski RP, Liu S, Ruenes GL, Kajander KJ, Brewer KL: Excitotoxic spinal cord injury: behavioral and morphological characteristics of a central pain model. Pain 1998;75:141-155.

20 Marsala M, Sorkin LS, Yaksh TL: Transient spinal ischemia in rat: characterization of spinal cord blood flow, extracellular amino acid release and concurrent histopathological damage. J Cereb Blood Flow Metab 1994; 14:614624.

21 Vierck CJ, Light AR: Allodynia and hyperalgesia within dermatomes caudal to a spinal cord injury in primates and rodents. Progr Brain Res 2000; 129:411-428.

22 Christensen MD, Hulsebosch CE: Chronic pain after spinal cord injury. J Neurotrauma 1997; 14:517-537.

23 Hulsebosch CE: Pharmacology of chronic pain after spinal cord injury: novel acute and chronic intervention strategies; in Yezierski RP, Burchiel KJ (eds): Spinal Injury Pain: Assessment, Mechanism, Management, Progress in Pain Research and Management. Seattle, IASP Press, 2002, vol 23, pp 189-204.

24 Tasker RR, de Carvalho G, Dostrovsky JO: The history of central pain syndromes, with observations concerning pathophysiology and treatment; in Casey KL (ed): Pain and Central Nervous System Disease: The Central Pain Syndromes. New York, Raven Press, 1991, pp 31-58.

25 Means E, Anderson D: The pathophysiology of acute spinal cord injury; in Davidhoff R (ed): Handbook of the Spinal Cord. New York, Marcel Dekker, 1987 vol 4/5, pp 19-61.

26 Hsu CY, Lin T-N, Xu J, Chao J, Hogan EL: Kinins and related inflammatory mediators in central nervous system injury; in Salzman SK, Faden AL (eds): The Neurobiology of Central Nervous System Trauma. New York, Oxford Press, 1994, pp 145-154.
27 Regan R, Choi DW: Excitoxicity and central nervous system trauma; in Salzman SK, Faden AL (eds): The Neurobiology of Central Nervous System Trauma. New York, Oxford Press, 1994, pp 173-181.

28 Popovich P, Stokes B, Whitacre C: Concept of autoimmunity following spinal cord injury: possible roles for $\mathrm{T}$ lymphocytes in the traumatized central nervous system. J Neurosci Res 1996;45:349-363.

29 Rehncrona S, Westerberg E, Akesson B, Siedjö BK: Brain cortical fatty acids and phospholipids during and following complete and severe incomplete ischemia. J Neuroscience 1982;38: 84-93.

30 Springer JE, Azbill RD, Kennedy SE, George J, Geddes JW: Rapid calpain I activation and cytoskeletal protein degradation following traumatic spinal cord injury: attenuation with riluzole pretreatment. J Neurochem 1997;69: 1592-1600.

31 Tator CH, Fehlings MG: Review of the secondary injury theory of acute spinal cord trauma with emphasis on vascular mechanisms. J Neurosurg 1991;75:15-26.

32 Young W: The post-injury responses in trauma and ischemia: Secondary injury or protective mechanism? CNS Trauma 1987;4:27-52.

33 Hayashi M, Ueyama T, Nemoto K, Tamaki T, Senba E: Sequential mRNA expression for immediate early genes, cytokines and neurotrophins in spinal cord injury. J Neurotrauma 2000; 17:203-218.

34 Morrow TJ, Paulson PE, Brewer KL, Yezierski RP, Casey KL: Chronic, selective forebrain responses to excitotoxic dorsal horn injury. Exp Neurol 2000;161:220-226.

-35 Abraham KE, Brewer KL, McGinty JF: Opioid peptide messenger RNA expression is increased at spinal and supraspinal levels following excitotoxic spinal cord injury. Neurosci 2000;99:189-197.

36 Abraham KE, McGinty JF, Brewer KL: Spinal and supraspinal changes in opioid mRNA expression are related to the onset of pain behaviors following excitotoxic spinal cord injury. Pain 2001;90:181-190.

-37 Plunkett JA, Yu C-G, Bethea JR, Yezierski RP: Effects of interleukin-10 (IL-10) on pain behavior and gene expression following excitotoxic spinal cord injury in the rat. Exp Neurol 2001;169:144-154.

38 Yakovlev AG, Faden AI: Sequential expression of c-fos protooncogene, TNF-alpha, and dynorphin genes in spinal cord following experimental traumatic injury. Mol Chem Neuropathol 1994;24:179-190.

39 Siddall PJ, Xu CL, Floyd N, Keay KA: C-fos expression in the spinal cord in rats exhibiting allodynia following contusive spinal cord injury. Brain Res 1999;851:281-286.

40 Bethea JR, Castro M, Lee TT, Dietrich WD, Yezierski RP: Traumatic spinal cord injury induces nuclear factor kappa B activation. J Neurosci 1998;18:3251-3260. 
41 Baeuerle PA, Baltimore D: The physiology of NFKB transcription factor; in Cohen $\mathrm{P}$, et al (eds): Molecular Aspects of Cellular Regulation-Hormonal Control of Gene Transcription. Amsterdam, Elsevier/North Holland, 1991, pp 409-432.

-42 Nesic O, Svrakic NM, Xu G-Y, McAdoo D, Westlund KN, Hulsebosch CE, Galante A, Soteropoulos P, Tolias P, Young Hart RP, Perez-Polo JR: DNA microarray analysis of the contused spinal cord: effect of NMDA receptor inhibition. J. Neurosci Res 2000;68:406-423.

-43 Hains BC, Klein JP, Saab CY, Craner MJ, Black JA, Waxman SG: Upregulation of sodium channel Nav1.3 and functional involvement in neuronal hyperexcitability associated with central neuropathic pain after spinal cord injury. J Neurosci 2003;23:8881-8892.

44 Anderson D, Hall E: Pathophysiology of spinal cord trauma. Ann Emerg Med 1993;22:987992.

-45 Tator C: Update on the pathophysiology and pathology of acute spinal cord injury. Brain Pathol 1995;5:407-413.

46 Hall E, Yonkers P, Andrus P, et al: Biochemistry and pharmacology of lipid antioxidants in acute brain and spinal cord injury. J Neurotrauma 1992;9:S425-S442.

47 Hall E, Braughle M: Free radicals in CNS injury; in Waxman S (ed): Molecular and Cellular Approaches to the Treatment of Neurological Disease. New York, Raven Press, 1993, pp 81-105.

-48 Mattson M: Modification of ion homoeostasis by lipid peroxidation: roles in neuronal degeneration and adaptive plasticity. Trends Neurosci 1998;21:53-57.

-49 Goldman S, Elowitz E, Flamm E: Effect of traumatic injury on membrane phosphatase activity in cat spinal cord. Exp Neurol 1983; 82:650-662.

50 Kwo S, Young W, DeCrescito V: Spinal cord sodium, potassium, calcium and water concentration in rats after graded contusion injury. $\mathrm{J}$ Neurotrauma 1989;6:13-24.

-51 Young W, Yen V, Blight A: Extracellular calcium ionic activity in experimental spinal cord contusion. Brain Res 1982;253:105-113.

-52 Stokes B, Fox R, Hallinden G: Extracellular calcium activity in the injured spinal cord. Exp Neurol 1983;80:561-572.

-53 Orrenius S, Nicotera P: The calcium ion and cell death. J Neural Transm 1994;43:1-11.

- 54 Panter S, Yum S, Faclen A: Alteration in extracellular amino acids after traumatic spinal cord injury. Ann Neurol 1990;27:96-99.

-55 Liu D, Valadez V, Sorkin L, et al: Norepinephrine and serotonin release upon impact injury to rat spinal cord. J Neurotrauma 1990;7:219227.

56 Sorkin L, Hughes M, Liu D, et al: Release and metabolism of 5-hydroxytryptamine in the cat spinal cord examined with microdialysis. J Pharmacol Exp Ther 1991;257:192-199.
57 Liu D, Vataclez V, Sorkin L, et al: Excitatory amino acids rise to toxic levels upon impact injury to the rat spinal cord. Brain Res 1991; 547:344-348.

$58 \mathrm{Xu}$ X-J, Hao H-X, Wiesenfeld-Hallin Z: Physiological and pharmacological characterization of a rat model of spinal cord injury pain after spinal ischemia; in Yezierski RP, Burchiel KJ (eds): Spinal Injury Pain: Assessment, Mechanism, Management, Progress in Pain Research and Management. Seattle, IASP Press, 2002, vol 23, pp 175-187.

59 Yezierski RP, Santana M, Park DH, Madsen PW: Neuronal degeneration and spinal cavitation following intraspinal injections of quisqualic acid in the rat. J Neurotrauma 1993; 10:445-456.

60 Hubscher $\mathrm{CH}$, Johnson RD: Changes in neuronal receptive field characteristics in caudal brain stem following chronic spinal cord injury. J Neurotrauma 1999;16:533-541.

61 Christensen MD, Everhart AW, Pickeman J, Hulsebosch CE: Mechanical and thermal allodynia in chronic central pain following spinal cord injury. Pain 1996;68:97-107.

62 Levitt M: Postcordotomy spontaneous dysesthesias in macaques: recurrence after spinal cord transection. Brain Res 1989;481:47-56.

63 Yu C-G, Fairbanks CA, Wilcox GL, Yezierski RP: Effects of agmatine, interleukin-10 and cyclosporin on spontaneous pain behavior following excitotoxic spinal cord injury in rats. $\mathrm{J}$ Pain 2003;4:129-140.

64 Hao J-X, Xu X-J, Aldskogius H, Seiger Å, Wiesenfeld-Hallin Z: The excitatory amino acid receptor antagonist MK-801 prevents the hypersensitivity induced by spinal cord ischemia in the rat. Exp Neurol 1991;114:182191.

65 Brewer KL, Yezierski RP: Effects of adrenal medullary transplants on pain-related behaviors following excitotoxic spinal cord injury. Brain Res 1998;798:83-92.

-66 Yu W, Hao X-J, Xu X-J, et al: Long-term alleviation of allodynia-like behaviors by intrathecal implantation of bovine chromaffin cells in rats with spinal cord injury. Pain 1998;74: 115-122.

67 Hains BC, Chastain KM, Evberhart AW, McAdoo DJ, Hulsebosch CE: Transplants of adrenal medullary chromaffin cells reduce forelimb and hindlimb allodynia in a rodent model of chronic central pain after spinal cord hemisection injury. Exp Neurol 2000;164: 426-437.

-68 Yezierski RP, Yu C-G, Mantyh PW, Vierck C, Lappi DA: Spinal neurons involved in the generation of at-level pain following spinal injury in the rat. Neurosci Lett 2004;361:232-236.

-69 Gorman AL, Yu C-G, Ruenes GR, Daniels L, Yezierski RP: Conditions affecting the onset, severity, and progression of a spontaneous pain-like behavior after excitotoxic spinal cord injury. J Pain 2001;2:229-240.

-70 Suzuki R, Morcuende S, Webber M, Hunt SP, Dickenson AH: Superficial NK-1-expressing neurons control spinal excitability through activation of descending pathways. Nat Neurosci 2002;5:1319-1326.
71 Porreca F, Burgess SE, Gardell LR, Vanderah TW, Malan TP Jr, Ossipov MH, Lappi DA, Lai $\mathrm{J}$ : Inhibition of neuropathic pain by selective ablation of brainstem medullary cells expressing the $\mu$-opioid receptor. J. Neurosci 2001;21: 5281-5288

72 Mason P: Central mechanisms of pain modulation. Curr Opin Neurobiol 1999;9:436-441.

73 Yezierski RP: Pain following spinal cord injury: pathophysiology and central mechanisms; in Sandkühler J, Bromm B, Gebhart GF (eds): Progress in Brain Research, Nervous System Plasticity and Chronic Pain. Amsterdam, Elsevier, 2000, vol 129, pp 429-449.

74 Milhorat T, Kotzen R, Harrison T, Capocelli A, Milhorat R: Dysesthetic pain in patients with syringomyelia. Neurosurgery 1996;38: 940-947.

75 Yezierski RP: Central neuropathic pain; in Burchiel K (ed): Surgical Management of Pain. New York, Thieme Medical Publishers, 2002, pp 42-64.

76 Vierck CJ, Light AR: Assessment of pain sensitivity in dermatomes caudal to spinal cord injury in rats; in Yezierski RP, Burchiel K (eds): Spinal Cord Injury Pain: Assessment, Mechanisms, Management. Seattle, IASP Press, 2002, pp 137-154.

77 Vierck CJ, Cannon RL, Stevens KA, AcostaRu AJ, Wirth ED: Mechanisms of increased pain sensitivity within dermatomes remote from an injured segment of the spinal cord; in Yezierski RP, Burchiel K (eds): Spinal Cord Injury Pain: Assessment, Mechanisms, Management. Seattle, IASP Press, 2002, pp 155173.

78 Mauderli AP, Acosta-Rua A, Vierck CJ: A conscious behavioral assay of thermal pain in rodents. J Neurosci Methods 2000;97:19-29.

79 Finnerup NM, Gyldensted C, Nielsen E, Kristensen $\mathrm{AD}$, Back FW, Jensen TS: MRI in chronic spinal cord injury patients with and without central pain. Neurology 2003;61: 1569-1575.

80 Pattany PM, Yezierski RP, Widerstrom-Noga EG, Bowen BC, Martinez-Arizala A, Garcia BR, Quencer RM: Proton magnetic resonance spectroscopy of the thalamus: evaluation of patients with chronic neuropathic pain following spinal cord injury. Am J Neuroradiol 2002;23: 901-905.

81 Ji R-R, Woolf CJ: Neuronal plasticity and signal transduction in nociceptive neurons: implications for the initiation and maintenance of pathological pain. Neurobiol Dis 2001;8:110.

82 Ji R-R, Kohno T, Moore KA, Woolf CJ: Central sensitization and LTP: do pain and memory share similar mechanisms? Trends Neurosci 2003;26:696-705.

83 Woolf CJ, Csotigan M: Transcriptional and posttranslational plasticity and the generation of inflammatory pain. Proc Natl Acad Sci USA 1999; 96:7723-7730.

84 Yu C-G, Yezierski RP: Activation of the ERK $1 / 2$ signaling cascade by excitotoxic spinal cord injury. Mol Brain Res 2005;138:244-255. 